\title{
Exchange of polycyclic aromatic hydrocarbons across the air-water interface in the Bohai and Yellow Seas
}

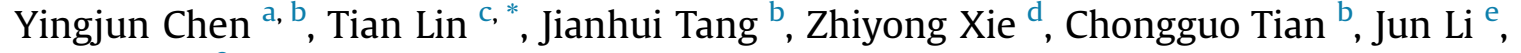 \\ Gan Zhang ${ }^{\mathrm{e}}$ \\ ${ }^{a}$ Key Laboratory of Cities' Mitigation and Adaptation to Climate Change in Shanghai, College of Environmental Science and Engineering, Tongji University, \\ Shanghai, China \\ ${ }^{\mathrm{b}}$ Key Laboratory of Coastal Environmental Processes and Ecological Remediation, Yantai Institute of Coastal Zone Research, Chinese Academy of Sciences, \\ Yantai, China \\ c State Key Laboratory of Environmental Geochemistry, Institute of Geochemistry, Chinese Academy of Sciences, Guiyang, China \\ ${ }^{\mathrm{d}}$ Helmholtz-Zentrum Geesthacht, Centre for Materials and Coastal Research, Institute of Coastal Research, Geesthacht, Germany \\ e State Key Laboratory of Organic Geochemistry, Guangzhou Institute of Geochemistry, Chinese Academy of Sciences, Guangzhou, China
}

\section{H I G H L I G H T S}

- We assess the fate of atmospheric PAHs in the air-water interface of BS and YS.

- The volatilization fluxes of three-ring PAHs were higher than the deposition fluxes.

- Petrogenic inputs contribute PAHs in the dissolved phase and sustain volatilization.

- The input to and output from the water reached equilibrium for four-ring PAHs.

- Five to six ring PAHs were introduced into the water primarily through deposition.

\section{A R T I C L E I N F O}

\section{Article history:}

Received 16 October 2015

Received in revised form 15 June 2016

Accepted 16 June 2016

Available online 17 June 2016

\section{Keywords:}

PAHs

Air-sea exchange

Net volatilization

Particle-water partitioning

The Bohai and Yellow Seas

\begin{abstract}
A B S T R A C T
In this study, air and surface seawater samples collected from the Bohai (BS) and Yellow Seas (YS) in May 2012 were determined exchange of PAHs, especially of low-molecular-weight (LMW) PAHs (three- and four-ring PAHs) at the air-water interface. Net volatilization fluxes of LMW PAHs were $266-1454 \mathrm{ng} / \mathrm{m}^{2}$ / $\mathrm{d}$ and decreased with distance from the coast, indicating that these PAHs transported from coastal runoff were potential contributors to the atmosphere in the BS and YS. Moreover, LMW PAHs were enriched in the dissolved phase compared with those in the particulate phase in the water column, possibly suggesting that the volatilized LMW PAHs were directly derived from wastewater discharge or petroleum pollution rather than released from contaminated sediments. The air-sea exchange fluxes of the threering PAHs were 2- to 20-fold higher than their atmospheric deposition fluxes in the BS and YS. The input to and output from the water reached equilibrium for four-ring PAHs. Differently, five- and six-ring PAHs were introduced into the marine environment primarily through dry and wet deposition, indicating that the water column was still a sink of these PAHs from the surrounding atmosphere.
\end{abstract}

() 2016 Elsevier Ltd. All rights reserved.

\section{Introduction}

The Bohai Sea (BS, 77,000 $\mathrm{km}^{2}$ ) and Yellow Sea (YS, $400,000 \mathrm{~km}^{2}$ ) are marginal seas of the Pacific Ocean located between mainland China and the Korean Peninsula (Fig. 1). The coastal and upwind zones of the BS and YS span four coastal

\footnotetext{
* Corresponding author.

E-mail address: lintian@vip.gyig.ac.cn (T. Lin).
}

provinces (Liaoning, Hebei, Shandong, and Jiangsu), inland provinces (e.g., Shanxi and Inner Mongolia), and two municipalities under the direct jurisdiction of the Central Government in China, which together supported almost one quarter of the Chinese population in 2001, provided 35\% of the national GDP in 2008, and were responsible for $42 \%$ of national coal consumption in 2001 . The region is one of the fastest growing and most severely contaminated in China. Among many atmospheric contaminants, polycyclic aromatic hydrocarbons (PAHs) are of particular concern in terms of 


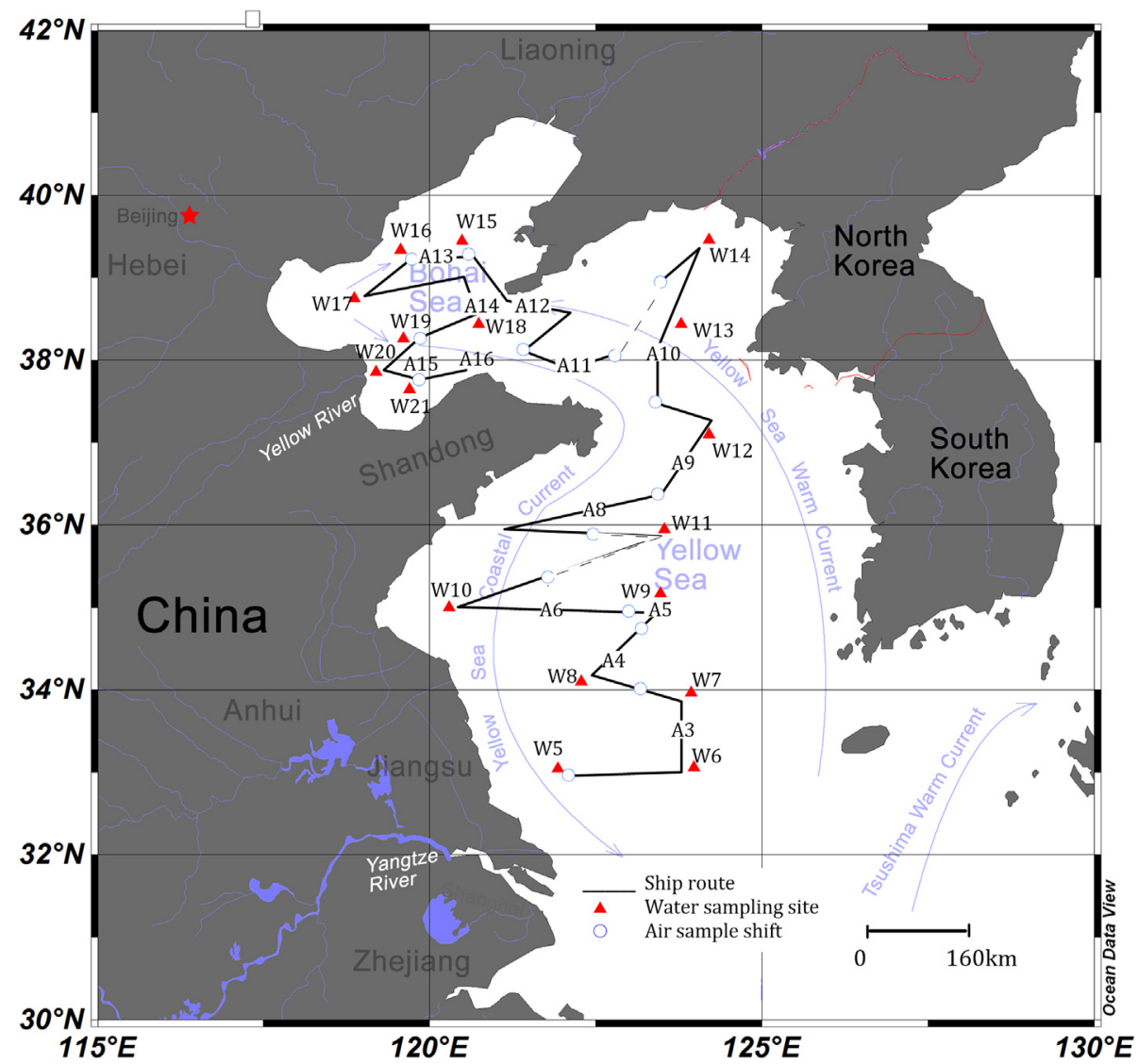

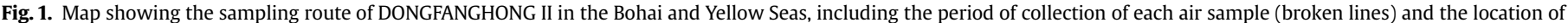

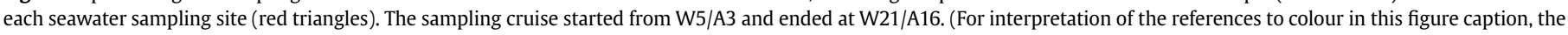
reader is referred to the web version of this article.)

their contribution to severe air pollution events in this region (Wang et al., 2014b; Tao et al., 2014), and PAH emissions have been increasing due to the rapid growth in coal consumption and the number of motor vehicles (Shen et al., 2011; Lin et al., 2012; Liu et al., 2012).

Under the influence of the East Asian monsoon, the BS and YS lie downwind of the East Asian continental outflow in spring and winter (Li et al., 2011; Lin et al., 2010). Therefore, atmospheric input is a significant nonpoint source of PAHs in the seas (Guo et al., 2006; Lin et al., 2011; Zhang et al., 2011). Lang et al. (2008) estimated that the annual Chinese PAH emission rate was $113,859 \mathrm{t} / \mathrm{y}$, and about $7.1 \%$ of the total PAH emissions (8092 $\mathrm{t}$ ) were transported out of mainland China, of which a large portion (69.9\%) reached within the BS, YS, and East China Sea (4664 t), and the South China Sea (991 t). Our recent studies focused on particulate-phase PAHs, and indicated that particle deposition played a dominant role in the source-to-sink process from the atmosphere into the sediments of the remote open sea of BS and YS (Lin et al., 2011). Particulate-phase PAHs are predicted to travel longer distances than gaseous-phase PAHs because the five- and six-ring PAHs that predominately existed in the particle phase are less photodegradable in the atmosphere and likely more resistant to microbial degradation/uptake in the water column than two- and three-ring PAHs (Baek et al., 1991; Tsapakis et al., 2003). However, Xu et al. (2006) reported that two- and three-ring species dominated the total PAH emissions in China (70\%), and these PAHs existed almost exclusively in the gaseous phase. To fill in this gap of gaseous PAHs in the marine system of this region, it is necessary to estimate the diffusive fluxes through the air-water interface and to compare them with the fluxes of dry and wet deposition. Furthermore, the discharged water/sediments from coastal runoff generally contain high petroleum contamination, acting as a potentially important factor in determining the source or sink of gaseous PAHs for the upper atmosphere (Hu et al., 2011; Qin et al., 2011). Thus, the main objective of this study was to quantitatively assess the fate of gaseous PAHs in the air-water interface of the BS and YS through 1) estimation of PAH diffusive fluxes across the air-water interface and comparison of these with the dry and wet deposition fluxes of atmospheric PAHs, and 2) analysis of the particle-water partitioning of PAHs in the water column to elucidate the potential sources of gaseous PAHs in the upper atmosphere of the BS and YS.

\section{Materials and methods}

\subsection{Sample collection}

A total of thirteen air samples (each collected over a period of $24 \mathrm{~h}$ ) were taken in May 2012 during the DONGFANGHONG II cruise in the BS and YS. The sampling route is shown in Fig. 1. A highvolume air sampler was placed windward on the uppermost deck of the ship, approximately $10 \mathrm{~m}$ above sea level. Air volumes of approximately $420 \mathrm{~m}^{3}$ were drawn through a glass fiber filter (GFF, Grade GF/A, $20.3 \times 25.4 \mathrm{~cm}$, bore size, $0.7 \mu \mathrm{m}$, Whatman, UK) to trap the airborne particles, and subsequently through a PUF/ Amberlite XAD-2 glass column (diameter $6.5 \mathrm{~cm}$, thickness $7.5 \mathrm{~cm}$, density $0.030 \mathrm{~g} / \mathrm{cm}^{3}$ ) for the gaseous-phase PAHs.

Seventeen surface seawater samples, each of approximately $70 \mathrm{~L}$, were collected using a metal bucket when the ship was 
stationary (Fig. 1). The seawater was immediately filtered through pre-combusted $\left(4 \mathrm{~h}\right.$ at $450{ }^{\circ} \mathrm{C}$ ) GFFs (Gelman Type A/E, diameter $150 \mathrm{~mm}$, nominal pore size $1.2 \mu \mathrm{m}$, Pall Gelman, USA) to collect the particulate-phase PAHs. The dissolved-phase compounds were then collected by a shelf-packed Serdolit PAD-2 glass column. The loaded GFFs and glass columns were stored at $4{ }^{\circ} \mathrm{C}$, and the filtered samples were stored at $-20^{\circ} \mathrm{C}$ prior to extraction.

\subsection{Sample extraction, quality control, and instrumental analysis}

Sample extraction was conducted strictly following standard analytical methods as reported in detail in the literature (Lin et al., 2011; Zhong et al., 2014). Three field blanks were run for each sample type (gas phase, air particle phase, seawater dissolved phase and suspended particle phase). Mean absolute blank values of PAHs ranged from 1 to $200 \mathrm{pg}$. Method detection limits (MDLs) were derived from mean field blank values plus three times the standard deviation $(\sigma)$ (for compounds showing no field blanks, the instrumental limits at a signal-to-noise ratio of three were used). Atmospheric MDLs ranged from 0.0015 to $0.5 \mathrm{pg} / \mathrm{m}^{3}$ and seawater MDLs ranged from 0.007 to $11 \mathrm{pg} / \mathrm{L}$. The 15 PAHs (three- and sixring PAHs) measured were acenaphthylene (Ac), acenaphthene (Ace), fluorine (Fl), phenanthrene (Phe), anthracene (Ant), fluoranthene (Flu), pyrene (Pyr), benz[a]anthracene $(\mathrm{BaA})$, chrysene $(\mathrm{Chr})$, benzo[b]fluoranthene (BbF), benzo[k]fluoranthene $(\mathrm{BkF})$, benzo[a]pyrene (BaP), indeno[1,2,3-cd]pyrene (IP), dibenz $[a, h]$ anthracene (DBA), and benzo[ghi]perylene (BghiP). The gas chromatograph-mass spectrometer (GC-MSD; Agilent GC $6890 \mathrm{~N}$ coupled with 5975C MSD, equipped with a DB5-MS column, $30 \mathrm{~m} \times 0.25 \mathrm{~mm} \times 0.25 \mathrm{~mm}$ ) used helium as the carrier gas. The GC operating processing was held at $60{ }^{\circ} \mathrm{C}$ for $2 \mathrm{~min}$, ramped to $290{ }^{\circ} \mathrm{C}$ at $3{ }^{\circ} \mathrm{C} \mathrm{min}-1$, and then held for $20 \mathrm{~min}$. The sample was injected splitless with the injector temperature at $290^{\circ} \mathrm{C}$. The postrun time was $5 \mathrm{~min}$ with the oven temperature at $310{ }^{\circ} \mathrm{C}$. The average surrogate recoveries were $76.5 \pm 11.5 \%$ for ACE-d10, $86.9 \pm 9.6 \%$ for PHE-d10, $84.7 \pm 8.3 \%$ for chrysene-d 12 , and $88.2 \pm 11.7 \%$ for perylene-d 12 .

\subsection{Data treatment}

In this study, a detailed description involved in data treatment was presented in Supplementary material , include air-sea exchange flux calculation, particle-water partitioning and dry deposition flux calculation (See Supplementary material S2.3).

\section{Results and discussion}

\subsection{Air-sea exchange}

The total gaseous concentrations of 15 PAHs over the BS and YS ranged from 780 to $2960 \mathrm{pg} / \mathrm{m}^{3}\left(1675 \pm 929 \mathrm{pg} / \mathrm{m}^{3}\right)$. It was expected that three- and four-ring PAHs were predominantly in gaseous phase. The higher concentrations of gas-phase PAHs observed at A11, A12, A15, and A16 may have been caused by the northwestern winds blowing across the Shandong Peninsula, carrying high gaseous PAH concentrations in the air mass (Fig. S1). The concentration levels of gas-phase PAHs were higher than those reported in the atmosphere of the North Pacific and the Arctic Oceans (Ding et al., 2007; Wang et al., 2013a), and comparable to those in the open Atlantic Ocean (Nizzetto et al., 2008), but lower than those observed in the Mediterranean and Black Seas (CastroJiménez et al., 2012).

The majority of PAHs exhibited a net volatilization trend, showing that the water column acted as a source of PAHs to the air during the observation period (Fig. 2). The total flux of 15 PAHs in

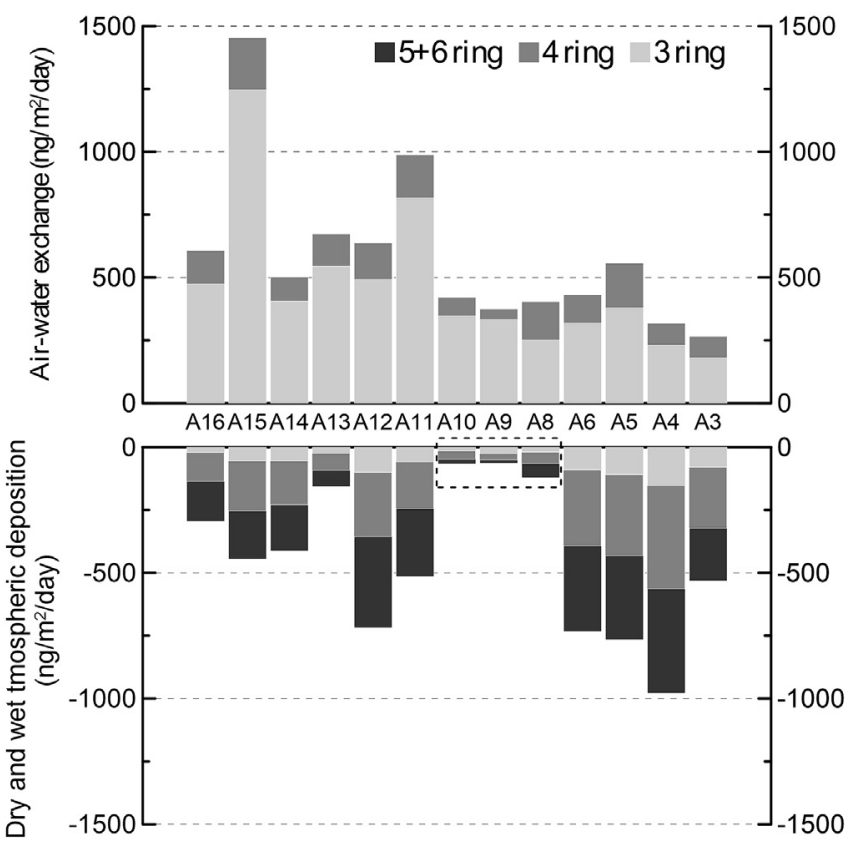

Fig. 2. Air-sea exchange and deposition fluxes $\left(\mathrm{ng} / \mathrm{m}^{2} / \mathrm{d}\right)$ of PAHs in the BS and YS, Negative flux indicates air to water, and positive flux indicates water to air.

the BS and YS ranged from 266 to $1454 \mathrm{ng} / \mathrm{m}^{2} / \mathrm{d}$ with a mean value of $594 \mathrm{ng} / \mathrm{m}^{2} / \mathrm{d}$. Fl and Phe had the highest diffusive fluxes (mean $236 \mathrm{ng} / \mathrm{m}^{2} / \mathrm{d}$, and $113 \mathrm{ng} / \mathrm{m}^{2} / \mathrm{d}$, respectively), followed by Flu, Ant, and Pyr. Because the concentrations of five- and six-ring PAHs (high-molecular-weight PAHs, HMW PAHs) in the gaseous phase were close or below the detection limit, very low fluxes of HMW PAHs were observed. Thus, as determined largely by their inherent physico-chemical properties, such as water solubility, vapor pressure, and Henry's law constant, the three- and four-ring PAHs (lowmolecular-weight PAHs, LMW PAHs) tended to undergo air-sea gas exchange, which is in agreement with other studies (Nelson et al., 1998; Bamford et al., 1999). Generally, net PAH volatilization occurs in open seawater, and net adsorption in water bodies in urban areas. For example, the total air-water exchange fluxes from Luhu Lake (an urban lake in Guangzhou) ranged from -5590 to $-33,700 \mathrm{ng} / \mathrm{m}^{2} / \mathrm{d}$, indicating that absorption may be an important process (Li et al., 2009); whereas on the tropical coast of Taiwan Island, they were $0.5-627 \mathrm{ng} / \mathrm{m}^{2} / \mathrm{d}$ for Phe and $21.5-121 \mathrm{ng} / \mathrm{m}^{2} /$ $\mathrm{d}$ for Pyr, which were of the same order of magnitude as those calculated in the present study (Cheng et al., 2013). A significant loading to water in urban areas may be caused by the higher gaseous-phase concentrations from neighboring sources, and the magnitude of the fluxes may have decreased with their gaseousphase concentrations due to the rapid scavenging/dilution with distance from the sources. Net volatilization occurs in remote water bodies because the half-lives of PAHs in those waters are about 10-100-fold longer than those in the atmosphere, and the PAHs in those waters are therefore more abundant relative to their concentrations in the atmosphere with increasing distance from the emission source (Mackay and Callcott, 1998). In this study, given that the water derived from the coastal runoff was heavily polluted, whereas the air masses arriving to the BS and YS after long-range transport were relatively clean during the sampling season, net volatilization of PAHs at the air-water interface was expected (Men et al., 2009; Sun et al., 2009; Wang et al., 2009).

Spatially, the magnitudes of the volatilization fluxes were higher in the BS than in the YS, and decreased with distance from the coast 
(Fig. S2). Furthermore, the diffusive fluxes of individual PAHs (Fl, Phe, Flu, and Pyr) showed significant positive correlations with their dissolved-phase concentrations $\left(\mathrm{R}^{2}=0.38-0.72, \mathrm{p}<0.05\right)$ (Fig. 3). This suggests that their concentration in the water played a key role in influencing the air-sea exchange flux of these threeand four-ring PAHs in the BS and YS. The results of the backtrajectory simulations suggested that the origin of air masses was variable both from open sea and Mainland China during the sampling campaign (Fig. S1); therefore, the concentration levels of PAHs in the atmosphere above the BS and YS were lower compared to those detected in continental outflow over a large area of the coast located upwind (Wang et al., 2011a,b). Under the circumstances volatilization of PAHs from seawater represented a significant contribution to the atmosphere over the BS and YS, as indicated by the profiles of gaseous PAH concentrations which demonstrated a proportionate decrease in concentration with increasing molecular weight (Gigliotti et al., 2002). As observation in this study, Fl and Phe had the highest concentrations in the gaseous PAHs, followed by Flu and Pyr, which differed from the observed profiles of gaseous PAHs (dominated by Phe and four-ring PAHs) from several background reference sites in coastal areas (Kim et al., 2012; Wang et al., 2013b). The PAH concentrations in the air over the seas were dominated by volatilization from the water, indicating that the water column contributed the major PAH burden in the atmosphere, especially in the BS during the sampling campaign.

\subsection{Partition of PAHs between dissolved and particulate phases}

The results of calculated air-sea exchange fluxes indicated that the coastal runoff acted as a potential source of the three- and fourring PAHs to the upper atmosphere in the BS and YS. An analysis of the particle-water partitioning of these PAHs can provide further information on the source-to-sink relationships within the water column (Mitra and Bianchi, 2003; Wang et al., 2008).

The observed PAH Koc values in the BS and YS showed an increasing trend with increasing molecular weight in their particle-water-phase partitioning (Fig. 4). Such findings are consistent

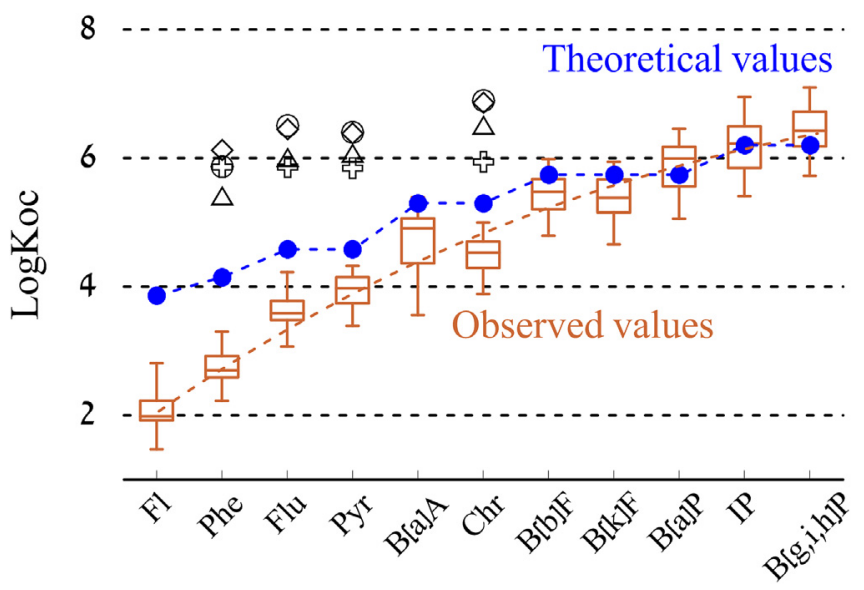

Fig. 4. Difference between theoretical and observed Koc values for PAHs in the BS and YS. $\bigcirc \triangle \square+$ represent Koc values from the Seine River (France, Fernandes et al., 1997), Rhone Delta (NW Mediterranean, Bouloubassi and Saliot, 1991), Pearl River Estuary (China, Luo et al., 2008), and Yangtze River Estuary (China, Yang et al., 2011), respectively.

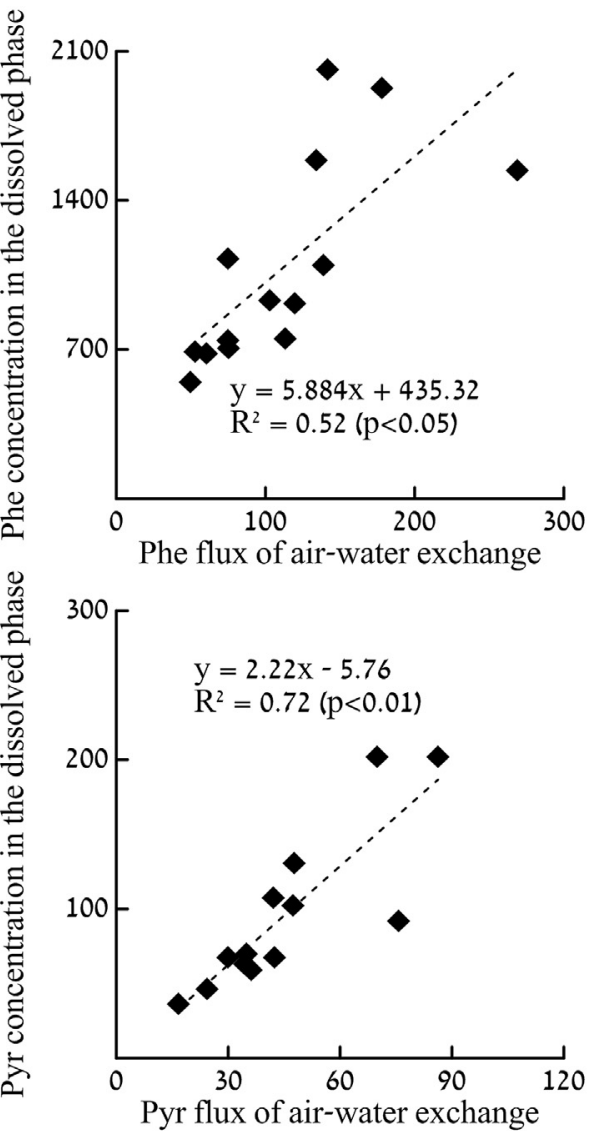

Fig. 3. Correlations of air-sea exchange fluxes $\left(\mathrm{ng} / \mathrm{m}^{2} / \mathrm{d}\right)$ with dissolved-phase concentrations of PAHs (pg/L) in the Bohai and Yellow Seas. 
with the laboratory-derived adsorption results of Karickhoff and Brown (1979) and Means et al. (1980), indicating that the accumulation of PAHs in particulate organic carbon is a function of the number of aromatic rings. In addition, the Koc values in the BS and YS deviated negatively from the theoretical equilibrium. They were significantly different from those of riverine samples collected from the Seine River (France, Fernandes et al., 1997), Rhone Delta (NW Mediterranean, Bouloubassi and Saliot, 1991), Pearl River Estuary (China, Luo et al., 2008), and Yangtze River Estuary (China, Yang et al., 2011), which deviated positively from the theoretical equilibrium (Fig. 4). More importantly, marked deviations between theoretical and observed values were only observed for the threeand four-ring PAHs, whereas the Koc values converged for the HMW PAHs (Fig. 4). Although the water and sediments travelled long distances from the coast into the seas, the expected chemical equilibrium between the particles and water in the marine system had not been achieved; in particular, the three- and four-ring PAHs in the dissolved phase were more abundant relative to the theoretical values of particle-water partitioning. The enrichment of these LWM PAHs may be due to the fact that they were derived from different sources compared with the sources of the HMW PAHs in the water column. Generally, PAH isomer pair ratios, such as Ant/(Ant + Phe ) and $\mathrm{BaA} /(\mathrm{BaA}+\mathrm{Chr})$, have been used as distinct chemical tracers to infer possible sources of PAHs in environmental samples (Yunker et al., 2002; Mai et al., 2003). The ratio of BaA/ $(\mathrm{BaA}+\mathrm{Chr})$ is reported as $<0.2$ for petrogenic sources, $>0.35$ for pyrogenic sources, and between 0.2 and 0.35 for mixed petroleumand combustion-derived sources. The Ant/(Ant + Phe) ratio of 0.1 is usually defined as the petroleum/combustion transition point (Yunker et al., 2002). In our study, these ratios showed that the PAHs in the dissolved phase had predominant sources from petroleum, but the PAHs in the particulate phase had mixed petroleum- and combustion-derived sources (Fig. 5). There were more petrogenic PAHs than pyrolytic ones in the dissolved phase because they are introduced directly into the marine environment by wastewater discharge from the coast or petroleum leakage on site. Widespread, direct petroleum pollution occurs in the study areas,

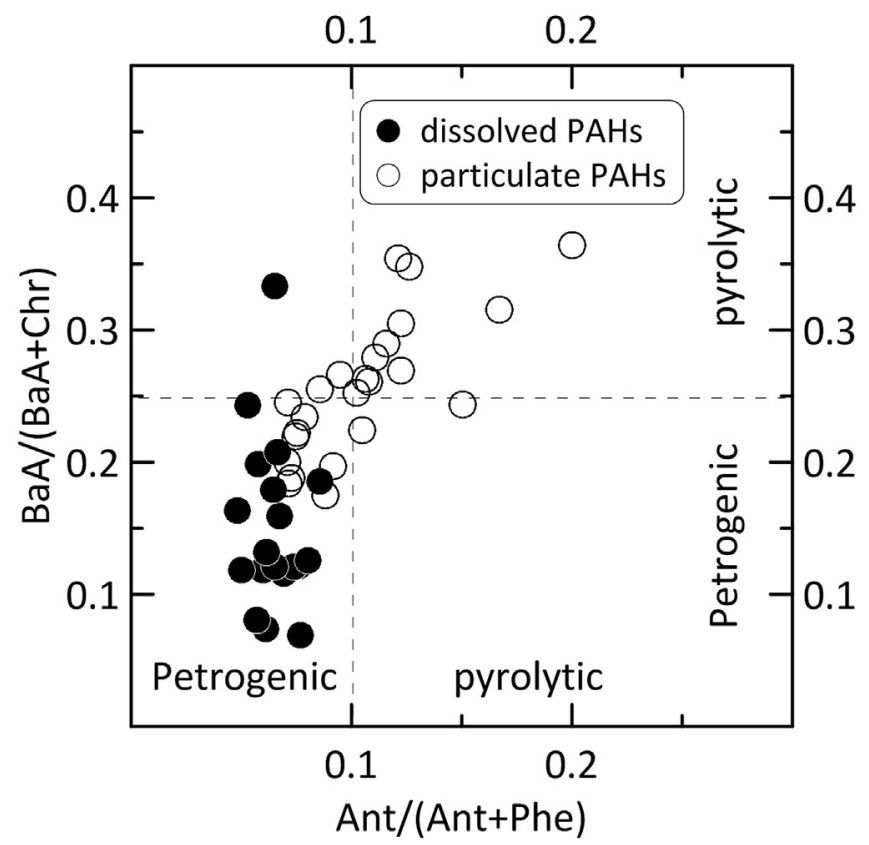

Fig. 5. Ant $/($ Ant + Phe $)$ and $B a A /(B a A+C h r)$ ratios for source identification in the water column. including oil leaks from ships, oil spills, and discharge of wastewater effluent (Liu et al., 2007, 2013, 2008). Thus, input of petroleum-derived PAHs contributed the three- and four-ring PAHs in the dissolved phase and resulted in the high fugacity of the LMW PAHs in the water column. In turn, high water-phase fugacity could cause re-emission of petrogenic PAHs (LMW PAHs) back to the atmosphere. In summary, the higher volatilization fluxes of $\mathrm{Fl}$, Phe, and Ant may have been caused mainly by the petrogenic PAH pollution in the BS from neighboring sources and were diluted with distance from coastal areas, reducing volatilization from the water to the atmosphere in the YS.

It is important to mention that the concentrations of PAHs in the dissolved phase (mostly three- and four-ring PAHs) were probably overestimated because the measured values included those PAHs existing as truly dissolved, colloidal, or associated with fine-grained $(<1.2 \mu \mathrm{m})$ particles (Fernandes et al., 1997). It is generally accepted that the salting-out effect reduces water solubility, but possibly increases the concentrations of dissolved PAHs due to the increased colloidal fraction when there is mixing of fresh and saline waters (Schwarzenbach et al., 2003). Consequently, increases in the dissolved/particulate ratios may be explained by increased colloidal fraction for the dissolved PAHs and preferential removal/settling of particulate PAHs. However, the salting-out effect, which has been widely observed in estuarine and coastal areas, was insufficient to explain the increased dissolved/particulate ratios observed in the water samples from the open seas in this study. In addition, the presence of those additional sorbents would be expected to increase the concentrations of the HMW compounds (which are more hydrophobic) more than those of the LMW compounds, which is not what we observed.

\subsection{Dry and wet deposition}

The concentrations of the 15 PAHs ranged from 60 to $1578 \mathrm{pg} /$ $\mathrm{m}^{3}\left(556 \pm 432 \mathrm{pg} / \mathrm{m}^{3}\right)$ in the particulate phase, accounting for $15-41 \%$ of the total PAH concentration (gas + particle) (except for sampling sites A8-A10, where it was only $2-8 \%$ ). This value was comparable to results from coastal cities in China, e.g., Beijing, Shanghai, and Xiamen, as well as the Gosan station on Jeju Island, Korea (Zhao et al., 2010; Chen et al., 2011; Ma et al., 2011; Choi et al., 2012). It should be noted that the value would be lower if the tworing $\mathrm{PAH}$ naphthalene were taken into account or be higher if sampling in cold seasons.

In the present study, the dry deposition fluxes of PAHs ranged from 9 to $272 \mathrm{ng} / \mathrm{m}^{2} / \mathrm{d}$ based on deposition velocities of $0.23-0.26 \mathrm{~cm} / \mathrm{s}$ (Wang et al., 2014a), which was comparable to those measured in the Eastern Mediterranean Basin in 2001 $\left(25-480 \mathrm{ng} / \mathrm{m}^{2} / \mathrm{d}\right.$, Tsapakis et al., 2006; Table $\left.1 \& \mathrm{~S} 1\right)$. The relatively low dry deposition fluxes were due to low concentrations in the particulate phase at the sampling sites (A8-A10: $<25 \mathrm{ng} / \mathrm{m}^{2} / \mathrm{d}$ ), likely owing to atmospheric removal processes during long-range transport over the sea. The results of the back-trajectory indicated that the low concentrations of particulate PAHs observed at these sampling sites were associated with air masses passing over the Yellow Sea from the Sea of Japan rather than from the highly contaminated region of East China before reaching the sampling locations (Fig. S1). The five- and six-ring PAHs are primarily associated with particles in the atmosphere; consequently, they were the most abundant PAHs in dry deposition and accounted for about $34-65 \%$ of the total PAH concentration, whereas the three-ring PAHs contributed less than $5 \%$ in total. Accordingly, the calculated dry deposition fluxes of HMW and LMW PAHs ranged from 4 to $166 \mathrm{ng} / \mathrm{m}^{2} / \mathrm{d}$ and from 6 to $105 \mathrm{ng} / \mathrm{m}^{2} / \mathrm{d}$, respectively.

In this study, the PAH concentrations in wet deposition were not measured directly. The wet deposition flux (Flux $\mathrm{WD}_{\mathrm{W}}$ ) was roughly 
Table 1

Results of calculated dry and wet deposition fluxes in the BS and YS ( $\left.\mathrm{ng} / \mathrm{m}^{2} / \mathrm{day}\right)$.

\begin{tabular}{|c|c|c|c|}
\hline & Dry deposition & Wet deposition & $\mathrm{R}^{*}$ \\
\hline & Range & Range & Ave \\
\hline$A C$ & $<1$ & $<1-9$ & 22.2 \\
\hline ACE & $<1$ & $<1-3$ & 22.3 \\
\hline $\mathrm{FL}$ & $<1$ & $1-12$ & 17.9 \\
\hline PHE & $1-8$ & $10-113$ & 13.5 \\
\hline ANT & $<1-7$ & $<1-41$ & 14.4 \\
\hline FLU & $1-27$ & $7-139$ & 5.4 \\
\hline PYR & $1-28$ & $6-119$ & 5.2 \\
\hline $\mathrm{BaA}$ & $<1-10$ & $1-18$ & 3.8 \\
\hline CHR & $1-25$ & $5-63$ & 3.3 \\
\hline $\mathrm{BbF}$ & $1-45$ & $4-89$ & 2.9 \\
\hline $\mathrm{BkF}$ & $1-26$ & $2-53$ & 3.1 \\
\hline $\mathrm{BaP}$ & $<1-27$ & $1-64$ & 4.5 \\
\hline IP & $1-40$ & $2-61$ & 2.0 \\
\hline $\mathrm{DbA}$ & $<1-4$ & $<1-4$ & 2.0 \\
\hline BgihP & $<1-25$ & $1-43$ & 2.6 \\
\hline
\end{tabular}

calculated using the reported ratios of FluxwD to Flux $_{D D}\left(R^{*}\right)$ from the same season in our unpublished study (Table 1 ). In general, the atmospheric particulate PAH profiles were found to be significantly correlated with those of wet $\left(\mathrm{R}^{2}=0.77, \mathrm{p}<0.0001\right)$ and dry $\left(\mathrm{R}^{2}=0.84, \mathrm{p}<0.0001\right)$ deposition, implying similar particle removal during the atmospheric deposition process (Tsapakis et al., 2006). Poster and Baker (1995) also pointed out that the atmospheric particulate concentrations and wet deposition fluxes were significantly correlated. In this study, the calculated wet deposition fluxes of the PAHs were $53-787 \mathrm{ng} / \mathrm{m}^{2} / \mathrm{d}$ (Table S1). The wet deposition fluxes were comparable to those measured in the Eastern Mediterranean Basin in $2001\left(\sim 450 \mathrm{ng} / \mathrm{m}^{2} / \mathrm{d}\right.$, Tsapakis et al., 2006), and significantly lower than those in urban sites; e.g., the mean values of the wet deposition fluxes in the wet and dry seasons were 5780 and $680 \mathrm{ng} / \mathrm{m}^{2} / \mathrm{d}$, respectively, for the total PAHs in Guangzhou, China, and the average dissolved-phase and particulate-phase wet deposition flux values were $7.4 \pm 7.3 \mu \mathrm{g} / \mathrm{m}^{2} /$ $\mathrm{d}$ and $21 \pm 30 \mu \mathrm{g} / \mathrm{m}^{2} /$ day, respectively, in Butal, Turkey (Li et al., 2009; Birgül et al., 2011). Thus, precipitation was an important factor influencing wet deposition flux besides concentration in rainwater. However, the profiles of the PAHs in the wet deposition were not fully similar with that of those of particulate PAHs in the atmosphere. The former were composed of both LMW PAHs (Fl, Phe, Flu, and Pyr) and HMW PAHs, such as BbF, INP, and BghiP. This is consistent with the fact that wet deposition involves both the dissolved and particulate phases. The LMW PAHs are assumed to be dissolved into raindrops according to Henry's constant, and the HMW PAHs are trapped by particles (Dickhut and Gustafson, 1995; Gustafson and Dickhut, 1997).

\subsection{Exchange of PAHs across the air-water interface}

Unlike the five- and six-ring PAHs which were introduced into the marine environment primarily through dry and wet deposition, the LMW PAHs had more complicated exchange processes at the air-water interface, which could depend on different site. Overall, the mean fluxes of air-sea exchange, dry deposition, and wet deposition for LMW PAHs were $-567,40$, and $176 \mathrm{ng} / \mathrm{m}^{2} / \mathrm{d}$, respectively (a negative value indicates $\mathrm{PAH}$ volatilization from the water). Spatially, the higher air-sea exchange flux of LMW PAHs was observed and was about two-to four-fold higher than the total atmospheric deposition fluxes of LMW PAHs in the BS. In the southern YS, the total LMW PAH deposition fluxes were nearly as much as the corresponding air-sea exchange fluxes (Fig. 2). In the northern YS (stations A8-A10), the lower air-sea exchange flux of
LMW PAHs but almost no atmospheric deposition was observed when clean air masses from the open ocean reached the stations (Fig. 2). It suggests that the advection of clean air masses was a likely removal mechanism for dissolved PAHs or LMW PAHs in the water column during the sampling period.

From the compound point of view, dry particle and wet deposition were less important processes for the three-ring PAHs compared with air-sea exchange. This observation is similar to that reported over the Eastern Mediterranean Basin (Tsapakis et al., 2006). In the present study, the air-sea exchange fluxes of the three-ring PAHs were 2- to 20-fold higher than their atmospheric deposition fluxes. The ratios were observed to be high of 10-20 in the coastal areas in the BS, and less than 4 in the open YS. This result suggests the diffusive processes of three-ring PAHs at air-water interface could become an important secondary source for coastal atmospheric environment. The input to and output from the water reached equilibrium or slightly net input for four-ring PAHs. In contrast, the dry and wet deposition contributed nearly $100 \%$ net input of the five- and six-ring PAHs at the air-water interface (Fig. 2). Combining the result of the particle-water partitioning that the five- and six-ring PAHs were distributed at equilibrium between the dissolved and particulate phases in the water column, suggesting that atmospheric deposition was an important removal mechanism, and sedimentation in the water column might be a significant sink of particulate PAHs in the BS and YS. This result was entirely consistent with our recent research (Lin et al., 2011).

\section{Conclusions}

The air-sea exchange fluxes of the three-ring PAHs were significant higher than their deposition fluxes in the BS and YS, suggesting the diffusive processes of three-ring PAHs at air-water interface could become an important secondary source for upper atmospheric environment in this study. The water column contributed the major LMW PAH burden in the atmosphere, especially in the BS during the sampling campaign. The diagnostic ratios of the PAHs indicated that the dissolved PAHs in the water column were derived from petrogenic sources, e.g., wastewater discharge from the coast and petroleum leakage into the sea. Input of petroleum-derived PAHs contributed the majority of the threeand four-ring PAHs in the dissolved phase and resulted in the high fugacity of the LMW PAHs in the water column. In turn, high waterphase fugacity could cause re-emission of petrogenic PAHs back to the air. Differently, the dry and wet deposition contributed nearly $100 \%$ net input of the five- and six-ring PAHs at the air-water interface. Combining the result of the particle-water partitioning that the five- and six-ring PAHs were distributed at equilibrium between the dissolved and particulate phases in the water column, it suggest that particle deposition played a dominant role in the source-to-sink process from the atmosphere into the sediments.

\section{Acknowledgement}

This work was financially supported by the Strategic Priority Research Programs of the Chinese Academy of Sciences (XDA11020402, XDB05030303), and the National Natural Scientific Foundations of China $(41273135,41473091)$.

\section{Appendix A. Supplementary data}

Supplementary data related to this article can be found at http:// dx.doi.org/10.1016/j.atmosenv.2016.06.039. 


\section{References}

Baek, S.O., Field, R.A., Goldstone, M.E., Kirk, P.W., Lester, J.N., Perry, R., 1991. A review of atmospheric polycyclic aromatic hydrocarbons: sources, fate and behavior. Water Air Soil Pollut. 60 (3-4), 279-300.

Bamford, H.A., Offenberg, J.H., Larsen, R.K., Ko, F.C., Baker, J.E., 1999. Diffusive exchange of polycyclic aromatic hydrocarbons across the air-water interface of the Patapsco River, an urbanized subestuary of the Chesapeake Bay. Environ. Sci. Technol. 33 (13), 2138-2144.

Birgül, A., Tasdemir, Y., Cindoruk, S.S., 2011. Atmospheric wet and dry deposition of polycyclic aromatic hydrocarbons (PAHs) determined using a modified sampler. Atmos. Res. 101 (1-2), 341-353.

Bouloubassi, I., Saliot, A., 1991. Composition and sources of dissolved and particulate $\mathrm{PAH}$ in surface waters from the Rhone delta (NW Mediterranean). Mar. Pollut. Bull. 22 (12), 588-594.

Castro-Jiménez, J., Berrojalbiz, N., Wollgast, J., Dachs, J., 2012. Polycyclic aromatic hydrocarbons (PAHs) in the Mediterranean Sea: atmospheric occurrence, deposition and decoupling with settling fluxes in the water column. Environ. Pollut. 166 (0), 40-47.

Chen, Y., Feng, Y., Xiong, S., Liu, D., Wang, G., Sheng, G., Fu, J., 2011. Polycyclic aromatic hydrocarbons in the atmosphere of Shanghai, China. Environ. Monit. Assess. 172 (1), 235-247.

Cheng, J.O., Ko, F.C., Lee, C.L., Fang, M.D., 2013. Air-water exchange fluxes of polycyclic aromatic hydrocarbons in the tropical coast, Taiwan. Chemosphere 90 (10), 2614-2622.

Choi, S.D., Ghim, Y.S., Lee, J.Y., Kim, J.Y., Kim, Y.P., 2012. Factors affecting the level and pattern of polycyclic aromatic hydrocarbons (PAHs) at Gosan, Korea during a dust period. J. Hazard. Mater. 227-228, 79-87.

Dickhut, R.M., Gustafson, K.E., 1995. Atmospheric washout of polycyclic aromatic hydrocarbons in the Southern Chesapeake Bay Region. Environ. Sci. Technol. 29 (6), 1518-1525.

Ding, X., Wang, X.M., Xie, Z.Q., Xiang, C.H., Mai, B.X., Sun, L.G., Zheng, M., Sheng, G.Y., Fu, J.M., Pöschl, U., 2007. Atmospheric polycyclic aromatic hydrocarbons observed over the North Pacific Ocean and the Arctic area: spatial distribution and source identification. Atmos. Environ. 41 (10), 2061-2072.

Fernandes, M.B., Sicre, M.A., Boireau, A., Tronczynski, J., 1997. Polyaromatic hydrocarbon (PAH) distributions in the Seine River and its Estuary. Mar. Pollut. Bull. 34 (11), 857-867.

Gigliotti, C.L., Brunciak, P.A., Dachs, J., Glenn, T.R., Nelson, E.D., Totten, L.A Eisenreich, S.J., 2002. Air-water exchange of polycyclic aromatic hydrocarbons in the New York-New Jersey, Usa, Harbor Estuary. Environ. Toxicol. Chem. 21 (2), 235-244.

Guo, Z., Lin, T., Zhang, G., Yang, Z., Fang, M., 2006. High-resolution depositional records of polycyclic aromatic hydrocarbons in the central continental shelf mud of the East China Sea. Environ. Sci. Technol. 40 (17), 5304-5311.

Gustafson, K.E., Dickhut, R.M., 1997. Gaseous exchange of polycyclic aromatic hydrocarbons across the air-water interface of Southern Chesapeake Bay. Environ. Sci. Technol. 31 (6), 1623-1629.

Hu, L., Guo, Z., Shi, X., Qin, Y., Lei, K., Zhang, G., 2011. Temporal trends of aliphatic and polyaromatic hydrocarbons in the Bohai Sea, China: evidence from the sedimentary record. Org. Geochem. 42 (10), 1181-1193.

Karickhoff, S.W., Brown, D.S., 1979. Determination of Octanol/water Distribution Coefficients, Water Solubilities, and Sediment/water Partition Coefficients for Hydrophobic Organic Pollutants. EPA-600/4-79-032, Athens.

Kim, J.Y., Lee, J.Y., Choi, S.D., Kim, Y.P., Ghim, Y.S., 2012. Gaseous and particulate polycyclic aromatic hydrocarbons at the Gosan background site in East Asia. Atmos. Environ. 49 (0), 311-319.

Lang, C., Tao, S., Liu, W., Zhang, Y., Simonich, S., 2008. Atmospheric transport and outflow of polycyclic aromatic hydrocarbons from China. Environ. Sci. Technol. 42 (14), 5196-5201.

Li, J., Cheng, H., Zhang, G., Qi, S., Li, X., 2009. Polycyclic aromatic hydrocarbon (PAH) deposition to and exchange at the air-water interface of Luhu, an urban lake in Guangzhou, China. Environ. Pollut. 157 (1), 273-279.

Li, S., Kim, J., Kim, K.R., Mühle, J., Kim, S.K., Park, M.K., Stohl, A., Kang, D.J., Arnold, T. Harth, C.M., Salameh, P.K., Weiss, R.F., 2011. Emissions of halogenated compounds in East Asia determined from measurements at Jeju Island, Korea. Environ. Sci. Technol. 45 (13), 5668-5675.

Lin, M., Holloway, T., Carmichael, G.R., Fiore, A.M., 2010. Quantifying pollution inflow and outflow over East Asia in spring with regional and global models. Atmos. Chem. Phys. 10 (9), 4221-4239.

Lin, T., Hu, L., Guo, Z., Qin, Y., Yang, Z., Zhang, G., Zheng, M., 2011. Sources of polycyclic aromatic hydrocarbons to sediments of the Bohai and Yellow Seas in East Asia. J. Geophys. Res. Atmos. 116 (D23), D23305.

Lin, T., Oin, Y., Zheng, B., Li, Y., Zhang, L., Guo, Z., 2012. Sedimentary record of polycyclic aromatic hydrocarbons in a reservoir in Northeast China. Environ. Pollut. 163 (0), 256-260.

Liu, L.Y., Wang, J.Z., Wei, G.L., Guan, Y.F., Wong, C.S., Zeng, E.Y., 2012. Sediment records of polycyclic aromatic hydrocarbons (PAHs) in the continental shelf of China: implications for evolving anthropogenic impacts. Environ. Sci. Technol. 46 (12), 6497-6504.

Liu, W.X. Chen, J.L. Lin, X.M., Tao, S., 2007. Spatial distribution and species composition of PAHs in surface sediments from the Bohai Sea. Mar. Pollut. Bull. 54 (1), 113-116.

Liu, W.X., Chen, J.L., Hu, J., Ling, X., Tao, S., 2008. Multi-residues of organic pollutants in surface sediments from littoral areas of the Yellow Sea, China. Mar. Pollut. Bull. 56 (6), 1091-1103.

Liu, X., Jia, H., Wang, L., Qi, H., Ma, W., Hong, W., Guo, J., Yang, M., Sun, Y., Li, Y.F., 2013. Characterization of polycyclic aromatic hydrocarbons in concurrently monitored surface seawater and sediment along Dalian coast after oil spill. Ecotoxicol. Environ. Saf. 90 (0), 151-156.

Luo, X.J., Mai, B.X., Yang, Q.S., Chen, S.J., Zeng, E.Y., 2008. Distribution and partition of polycyclic aromatic hydrocarbon in surface water of the Pearl River Estuary, South China. Environ. Monit. Assess. 145 (1-3), 427-436.

Ma, W.L., Sun, D.Z., Shen, W.G., Yang, M., Qi, H., Liu, L.Y., Shen, J.M., Li, Y.F., 2011 Atmospheric concentrations, sources and gas-particle partitioning of PAHs in Beijing after the 29th olympic games. Environ. Pollut. 159 (7), 1794-1801.

Mackay, D., Callcott, D., 1998. Partitioning and physical chemical properties of PAHs. In: The Handbook of Environmental Chemistry: PAHs and Related Compounds. Springer, pp. 325-346.

Mai, B.X., Qi, S.H., Zeng, E.Y., Yang, Q.S., Zhang, G., Fu, J.M., Sheng, G.Y., Peng, P.A., Wang, Z.S., 2003. Distribution of polycyclic aromatic hydrocarbons in the coastal region off Macao, China: assessment of input sources and transport pathways using compositional analysis. Environ. Sci. Technol. 37 (21), 4855-4863.

Means, J.C., Wood, S.G., Hassett, J.J., Banwart, W.L., 1980. Sorption of polynuclear aromatic hydrocarbons by sediments and soils. Environ. Sci. Technol. 14 (12), 1524-1528.

Mitra, S., Bianchi, T.S., 2003. A preliminary assessment of polycyclic aromatic hydrocarbon distributions in the lower Mississippi River and Gulf of Mexico. Mar. Chem. 82 (3-4), 273-288.

Men, B., He, M., Tan, L., Lin, C., Quan, X., 2009. Distributions of polycyclic aromatic hydrocarbons in the Daliao River Estuary of Liaodong Bay, Bohai Sea (China). Mar. Pollut. Bull. 58 (6), 818-826.

Nelson, E.D., McConnell, L.L., Baker, J.E., 1998. Diffusive exchange of gaseous polycyclic aromatic hydrocarbons and polychlorinated biphenyls across the air-water interface of the Chesapeake Bay. Environ. Sci. Technol. 32 (7), 912-919.

Nizzetto, L., Lohmann, R., Gioia, R., Jahnke, A., Temme, C., Dachs, J., Herckes, P., Guardo, A.D. Jones, K.C. 2008. PAHs in air and seawater along a North-South Atlantic transect: trends, processes and possible sources. Environ. Sci. Technol. 42, 1580-1585.

Poster, D.L., Baker, J.E., 1995. Influence of submicron particles on hydrophobic organic contaminants in precipitation. 1. Concentrations and distributions of polycyclic aromatic hydrocarbons and polychlorinated biphenyls in rainwater. Environ. Sci. Technol. 30 (1), 341-348.

Qin, Y., Zheng, B., Lei, K., Lin, T., Hu, L., Guo, Z., 2011. Distribution and mass inventory of polycyclic aromatic hydrocarbons in the sediments of the South Bohai Sea, China. Mar. Pollut. Bull. 62 (2), 371-376.

Schwarzenbach, R., Gschwend, P.M., Imboder, D.M., 2003. Environmental Organic Chemistry, second ed. Wiley Interscience, New Jersey.

Shen, H., Tao, S., Wang, R., Wang, B., Shen, G., Li, W., Su, S., Huang, Y., Wang, X., Liu, W., Li, B., Sun, K., 2011. Global time trends in PAH emissions from motor vehicles. Atmos. Environ. 45 (12), 2067-2073.

Sun, J.H., Wang, G.L., Chai, Y., Zhang, G., Li, J., Feng, J., 2009. Distribution of polycyclic aromatic hydrocarbons (PAHs) in Henan reach of the Yellow River, Middle China. Ecotoxicol. Environ. Saf. 72 (5), 1614-1624.

Tao, M., Chen, L., Wang, Z., Ma, P., Tao, J., Jia, S., 2014. A study of urban pollution and haze clouds over northern China during the dusty season based on satellite and surface observations. Atmos. Environ. 82 (0), 183-192.

Tsapakis, M., Apostolaki, M., Eisenreich, S., Stephanou, E.G., 2006. Atmospheric deposition and marine sedimentation fluxes of polycyclic aromatic hydrocarbons in the Eastern Mediterranean Basin. Environ. Sci. Technol. 40 (16), $4922-4927$.

Tsapakis, M., Stephanou, E.G., Karakassis, I., 2003. Evaluation of atmospheric transport as a nonpoint source of polycyclic aromatic hydrocarbons in marine sediments of the Eastern Mediterranean. Mar. Chem. 80 (4), 283-298.

Wang, F., Lin, T., Li, Y., Ji, T., Ma, C., Guo, Z., 2014a. Sources of polycyclic aromatic hydrocarbons in PM2.5 over the East China Sea, a downwind domain of East Asian continental outflow. Atmos. Environ. 92 (0), 484-492.

Wang, H., Tan, S.C., Wang, Y. Jiang, C. Shi, G.Y., Zhang, M.X. Che, H.Z., 2014b. A multisource observation study of the severe prolonged regional haze episode over eastern China in January 2013. Atmos. Environ. 89 (0), 807-815.

Wang, J.Z., Nie, Y.F., Luo, X.L., Zeng, E.Y., 2008. Occurrence and phase distribution of polycyclic aromatic hydrocarbons in riverine runoff of the Pearl River Delta, China. Mar. Pollut. Bull. 57 (6-12), 767-774.

Wang, L., Yang, Z., Niu, J., Wang, J., 2009. Characterization, ecological risk assessment and source diagnostics of polycyclic aromatic hydrocarbons in water column of the Yellow River Delta, one of the most plenty biodiversity zones in the world. J. Hazard. Mater. 169 (1-3), 460-465.

Wang, W., Simonich, S., Giri, B., Chang, Y., Zhang, Y., Jia, Y., Tao, S., Wang, R., Wang, B., Li, W. Cao, J. Lu, X., 2011a. Atmospheric concentrations and air-soil gas exchange of polycyclic aromatic hydrocarbons (PAHs) in remote, rural village and urban areas of Beijing-Tianjin region, North China. Sci. Total Environ. 409 (15), 2942-2950

Wang, W., Simonich, S.L.M., Wang, W., Giri, B., Zhao, J., Xue, M., Cao, J., Lu, X., Tao, S., 2011b. Atmospheric polycyclic aromatic hydrocarbon concentrations and gas/ particle partitioning at background, rural village and urban sites in the North China Plain. Atmos. Res. 99 (2), 197-206.

Wang, Z., Na, G., Ma, X., Fang, X., Ge, L., Gao, H., Yao, Z., 2013a. Occurrence and gas/ particle partitioning of PAHs in the atmosphere from the North Pacific to the 
Arctic Ocean. Atmos. Environ. 77, 640-646.

Wang, Z., Ren, P.F. Sun, Y., Ma, X.D., Liu, X., Na, G.S., Yao, Z.W., 2013b. Gas/particle partitioning of polycyclic aromatic hydrocarbons in coastal atmosphere of the North Yellow Sea, China. Environ. Sci. Pollut. Res. 20 (8), 5753-5763.

Xu, S.S., Liu, W.X., Tao, S., 2006. Emission of polycyclic aromatic hydrocarbons in China. Environ. Sci. Technol. 40 (3), 702-708.

Yang, Y., Liu, M., Wang, L.L., Fu, J.L., Yan, C.X., Zhou, J.L., 2011. Sorption behavior of phenanthrene in Yangtze estuarine sediments: sequential separation. Mar. Pollut. Bull. 62 (5), 1025-1031.

Yunker, M.B., Macdonald, R.W., Vingarzan, R., Mitchell, R.H., Goyette, D., Sylvestre, S., 2002. PAHs in the Fraser River basin: a critical appraisal of PAH ratios as indicators of PAH source and composition. Org. Geochem. 33 (4),
$489-515$

Zhang, Y., Shen, H., Tao, S., Ma, J., 2011. Modeling the atmospheric transport and outflow of polycyclic aromatic hydrocarbons emitted from China. Atmos. Environ. 45 (17), 2820-2827.

Zhao, J., Zhang, F., Chen, J., Xu, Y., 2010. Characterization of polycyclic aromatic hydrocarbons and gas/particle partitioning in a coastal city, Xiamen, Southeast China. J. Environ. Sci. 22 (7), 1014-1022.

Zhong, G., Tang, J., Xie, Z., Möller, A., Zhao, Z., Sturm, R., Chen, Y., Tian, C., Pan, X., Qin, W., Zhang, G., Ebinghaus, R., 2014. Selected current-use and historic-use pesticides in air and seawater of the Bohai and Yellow Seas, China. J. Geophys. Res. Atmos. 119 (2), 2013JD020951. 